\title{
Effect of K1, K2 Anti-Bacterial Agents on Tobacco Ralstonia Solanacearum
}

\author{
Anan Wang ${ }^{1}$, Zhifeng Zhao ${ }^{1}$, Zhenzhen Liu ${ }^{1}$, Yixin Liu ${ }^{1 *}$ \\ School of Earth and Space Science, University of Science and Technology of China, Hefei, China \\ E-mail:wanganan@mail.ustc.edu.cn, liuyixin@ustc.edu.cn \\ Received July 30, 2010; revised October 8, 2010; accepted October 26, 2010
}

\begin{abstract}
The tobacco Ralstonia Solanacearum were both cultured on nutrient agar plates and inoculated in seedling stage of tobacco, then treated with $\mathrm{K} 1$ and $\mathrm{K} 2$, two anti-bacterial agents, at a serial concentrations to study their inhibitory efficiency. The result indicated that $\mathrm{K} 1$ can inhibit $R$. Solanacearum growth entirely, at the concentration range from $1 / 50$ to $1 / 5000 . \mathrm{K} 2$ can reach the same result at the concentration range from 1/50 to $1 / 50000$. Compared with the control plates, $\mathrm{K} 1$, at the concentration $1 / 50000$, had no significant differences, and the average number of colony per plate was 112-115. The immature tobacco shown wilt as soon as inoculated with $R$. Solanacearum, and recovered gradually after using K1, K2. The densities of microbial suspension, handled by K1, K2 within $10 \mathrm{hs,} \mathrm{were} \mathrm{both} \mathrm{significantly} \mathrm{lower} \mathrm{than} \mathrm{the} \mathrm{controlled} \mathrm{ones.} \mathrm{The} \mathrm{op-}$ tical microscopy also shown that handled microbial body differed from the controlled, whose body was regular short, rod shape as opposed to the handled ones with irregular rod shape and damaged body. All the results indicated that $\mathrm{K} 1$ and $\mathrm{K} 2$ both had inhibitory effects on tobacco R. Solanacearum, and K2 was more efficient than K1.
\end{abstract}

Keywords: Anti-Bacterial Agents K1, K2, Inhibition, Tobacco Ralstonia Solanacearum

\section{Introduction}

Bacterial wilt of tobacco or Granville wilt, caused by Ralstonia Solanacearum, a wilt-inducing bacterial pathogen of plants in family Solanaceae (including tomato, eggplant, and sweetpepper ), is one of the most common soil-borne plant diseases in both tropical and subtropical tobacco regions $[1,2]$. It harms the root, stalk, leaves of tobacco, while the most obvious symptom is the twisted or even distorted leaf. When this disease occurs, the root pith of infected plant discolors; the vascular tissue is destroyed biochemically at the ground level followed by blocking at first. As the disease progresses, the entire plant wilts and death generally follows [3]. The characteristic symptom of infected leaves at the initial stage is wilting with a light green color. That gives a name "bacterial wilt" to this disease. Granville wilt is spreading fast and becoming more seriously in tobacco-plantation areas located at the south of Yangtze valley recently.

The time from infecting to outbreak lasts long. These bacteria are favored in relatively high soil temperatures and adequate to high moisture levels in the soil. The outbreak is often very seriously and causes big economic losses every year when it comes to high temperature and high humidity in soil. Therefore, bacterial wilt disease has become one of the main obstacles to finish the expected size of tobacco area; to stabilize the output of old tobacco regions; to promote the quality of tobacco.

There are several measures to control Granville wilt in home and international countries, such as chemical control [4,5]; biological control [6,7] and integrated managements [8-10]. However, the using of chemical agents, such as agricultural streptomycin and oxytetracycline, will easily accumulate in soil and reduce the security of tobacco. After a long-term usage, it will strengthen the resistant ability of pathogens [11] and disorder micro-ecosystem of soil. One of the biological control like antagonistic bacteria which are mainly isolated from soil and rhizosphere is not very successful in field conditions although it shows some suppressive effects in greenhouse and plot experiments.

The serious struggle between grain and tobacco on land use make the rational crop rotation hardly to realize comprehensively. The long time of breeding the disease-resistant variety will hardly to meet the demand 
promptly. Even the National Tobacco Corporation doesn't have control agents to recommend recently. Therefore, it is still difficult to control domestic Granville wilt with effective measures. Developing new antibacterial agents in agriculture will make great practical sense.

In recent years, our laboratory prepared and screened several antibacterial powders and photocatalystic nanoinhibitors to control soil-borne diseases in tobacco field in order to restore the normal state of soil micro-ecosystem. We have got some achievements at this stage after testing in tobacco fields and vegetable production areas of five provinces in China. This paper focused on the preliminary progress of $\mathrm{K} 1$ and $\mathrm{K} 2$ on Granville wilt in laboratory.

\section{Material and Methods}

\subsection{Pathogen and Reagents}

Ralstonia solanacearum RS71, used throughout this experiment, was offered by the Institute of Plant Protection (IPP), Chinese Academy of Agricultural Sciences (CAAS). $\mathrm{K} 1$ and $\mathrm{K} 2$, glycosaminoglycan-like antibacterial agents, were both prepared and screened by our laboratory. The accurate chemical structures of these agents were needed to be clarified.

\subsection{Culture Medium}

Nutrient agar: $\mathrm{NaCl} 5 \mathrm{~g}$; beef extract $3 \mathrm{~g}$; peptone $10 \mathrm{~g}$; agar 15 20 g; distilled water $1000 \mathrm{ml}$; pH $6.6 \pm 0.2$; autoclave at $121^{\circ} \mathrm{C}$ for 30 minutes [12] .

\subsection{Preparing Suspension of $\boldsymbol{R}$. Solanacearum}

For recovering the activity of the bacterial wilt pathogen, add $500 \mu$ l suspension of $R$. Solanacearum (strain RS71) stock solution to a bottle of nutrient broth and grown in a greenhouse controlled at $35^{\circ} \mathrm{C}$ for 72 hours. Make a $1: 10$ dilution of the $72 \mathrm{hr}$-suspension and inoculate $80 \mu \mathrm{l} \mathrm{di}-$ luted suspension to nutrient agar plates under aseptic operation. Those agar plates then were placed at $35^{\circ} \mathrm{C}$ for 72 hours. Single slimy dark brown colonies were transferred to nutrient broth at $35^{\circ} \mathrm{C}$ for 18 hours. After counting the number with blood cell counting instrument, a final suspension of $1 \times 10^{8} \mathrm{bacteria} / \mathrm{ml}$ needed to get ready.

\subsection{Inhibition Test of $K 1$ and $K 2$ on Tobacco $R$. Solanacearum}

In order to determine the most effective minimum con- centrations of $\mathrm{K} 1$ and $\mathrm{K} 2$ on tobacco $R$. Solanacearum, a enumeration technique called suspension-dilution and plate-count method [12] based on colonies formed under the presence of a series different concentrations of inhibitor placed in nutrient agars was used. These two antibacterial compounds were respectively added to these bottles of nutrient agar at about $45^{\circ} \mathrm{C}$ (warm enough to keep the agar fluid but cool enough not to destroy heat-sensitive amendments to the agar) under aseptic operation to get a series final concentrations of $1 / 50$, $1 / 500,1 / 5000$ and 1/50000. A batch of nutrient agar plates containing different concentrations of $\mathrm{K} 1$ and $\mathrm{K} 2$ were prepared. Make a series 1:10 dilutions of the suspension $\left(1 \times 10^{8}\right.$ bacteria $\left./ \mathrm{ml}\right)$ to different concentrations $\left(10^{7}, 10^{6}, 10^{5}, 10^{4}, 10^{3}, 10^{2}\right.$ bacteria/ml $)$ and distribute $80 \mu \mathrm{l}$ of the appropriate concentration $\left(1 \sim 2 \times 10^{3}\right.$ bacte$\mathrm{ria} / \mathrm{ml}$ ) to the prepared agar plates evenly. Counting and photographing took place after all these inoculation plates were incubated upside down at $35^{\circ} \mathrm{C}$ for 24 hours. Each test was repeated three times and non-amendment but inoculation was used as a control.

To identify the effect on the morphology of bacterial body, optical microscopy techniques were conducted. Three tubes sterilized at $121^{\circ} \mathrm{C}$ were prepared. Add K1 and $\mathrm{K} 2$ to these two tubes respectively which were containing $8 \mathrm{ml}$ freshly cultured suspensions of $R$. Solanacearum cells $\left(1 \sim 2 \times 10^{7}\right.$ bacteria/ml $)$ in order to reach a final concentration of $1 / 40000$. The third tube containing $8 \mathrm{ml}$ suspension was filled with sterilized deionized water to the same volume just as the other two and used as a control. Taking photos after all tubes incubated at a greenhouse controlled at $35^{\circ} \mathrm{C}$ for 10 hours. Using optical microscope (Olinpas FSX-100) to observe changes of the shape of microbial cells and taking photos.

Using hydroponic culture of tobacco to test the effect of $\mathrm{K} 1$ and $\mathrm{K} 2$ on seedlings infected with $R$. Solanacearum. Inoculation with a $500 \mu \mathrm{l}$ of freshly cultured suspension of $R$. Solanacearum cells $\left(1 \times 10^{8}\right.$ bacteria $\left./ \mathrm{ml}\right)$ to each seedling through injecting into the basal part of stem when the $6^{\text {th }}$ or $7^{\text {th }}$ leaf was unfolding. The wound turned dark after inoculation immediately. Spray the solution of K1 (1/1000) and K2 (1/1000) respectively to the infected tobacco seedlings which shown wilting 3 days later. The controlled seedlings were sprayed with water. Each test was repeated three times and 9 seedlings in sum. Taking photos after a 15-day growth period.

\subsection{Statistical Analysis}

All variables were calculated using statistical software-Statistical Package for Social Science (SPSS 12.0). All counts of clone represented means \pm standard deviation $(\bar{x} \pm \mathrm{S})$ and were compared with Students t-test at 
the $5 \%$ level to determine the significant differences.

\section{Results and Analysis}

\subsection{Effect of Different Diluted Concentrations of $\mathrm{K} 1$ and $\mathrm{K} 2$ on Tobacco Ralstonia Solanacearum}

Figure 1 and Table 1 showed the effect of different diluted concentrations of $\mathrm{K} 1$ and $\mathrm{K} 2$ on the count of colonies of tobacco $R$. Solanacearum formed on plates. In the presence of antibacterial agents (K1 and K2), symptoms of inhibition were observed.

The result indicated that K1 can inhibit $R$. Solanacearum growth entirely, at the concentration range from $1 / 50$ to $1 / 5000$. Compared with the control plates, K1, at the concentration $1 / 50000$, had no significant differences. Severe significant inhibitory effect (100\% inhibition rate) appeared in the presence of $\mathrm{K} 2$ at the concentration range from $1 / 50$ to $1 / 50000$. Further investigation is needed for this test hasn't got the most effective minimum concentration of $\mathrm{K} 2$ on bacterial wilt pathogen. All the results indicated that $\mathrm{K} 1$ and $\mathrm{K} 2$ both had inhibitory effects on tobacco $R$. Solanacearum, and K2 was more efficient than $\mathrm{K} 1$.

\subsection{Effect of K1 and K2 on Morphology of Ralstonia Solanacearum}

The effect of K1 and K2 on morphology of tobacco $R$. Solanacearum could be observed from Figure 2 and Figure 3. The photo here showed that this bacterial wilt pathogen grow very normally because the turbidity of the controlled suspension. The scale of turbidity of suspension treated by K1 was little low than the control. This result of ineffective concentration of K1 (1/40000) was congruent with the former test on plates when the concentration of $\mathrm{K} 1$ reached $1 / 50000$. The tube containing suspension in the presence of K2 was almost transparent and clear. This symptom indicated that $\mathrm{K} 2$ had a very serve inhibition effect on the growth of tobacco $R$. Solanacearum. The concentration of $\mathrm{K} 2$ used in suspension (1/40000) was very effective and again consistent with the former result on agar plates (no colonies appeared at concentration 1/50000).

Figure 3 showed the changes of morphology of this pathogen in the presence and absence of K1 and K2. The high density of bacteria which had regular short, rod body (length: about 1 2 $\mu \mathrm{m}$ ) in the absence of antibacterial agent could be observed clearly. No complete body

Table 1. Effect of different diluted concentration K1, K2 on the cfu of tobacco Ralstonia Solanacearum.

\begin{tabular}{|c|c|c|c|c|c|c|c|c|c|}
\hline \multirow[t]{2}{*}{ Treatments } & \multirow{2}{*}{$\begin{array}{c}\begin{array}{c}\text { Concentrations } \\
\mathrm{v} / \mathrm{v}\end{array} \\
1 / 50\end{array}$} & \multicolumn{6}{|c|}{ Counts/plate } & \multirow{2}{*}{$\begin{array}{c}\bar{x} \pm \mathrm{S} \\
0\end{array}$} & \multirow{2}{*}{$\begin{array}{c}\text { Significant } \\
\text { differences } \\
(\mathrm{P}<0.05)\end{array}$} \\
\hline & & 0 & 0 & 0 & 0 & 0 & 0 & & \\
\hline \multirow{3}{*}{$\mathrm{K} 1$} & $1 / 500$ & 0 & 0 & 0 & 0 & 0 & 0 & 0 & $\mathrm{~B}$ \\
\hline & $1 / 5000$ & 0 & 0 & 0 & 0 & 0 & 0 & 0 & B \\
\hline & $1 / 50000$ & 101 & 111 & 119 & 121 & 106 & 117 & $112.5 \pm 5.04$ & A \\
\hline \multirow{4}{*}{$\mathrm{K} 2$} & $1 / 50$ & 0 & 0 & 0 & 0 & 0 & 0 & 0 & B \\
\hline & $1 / 500$ & 0 & 0 & 0 & 0 & 0 & 0 & 0 & B \\
\hline & $1 / 5000$ & 0 & 0 & 0 & 0 & 0 & 0 & 0 & B \\
\hline & $1 / 50000$ & 0 & 0 & 0 & 0 & 0 & 0 & 0 & B \\
\hline \multicolumn{2}{|c|}{ CK (sterilized water) } & 108 & 102 & 120 & 124 & 125 & 115 & $115.7 \pm 6.96$ & A \\
\hline
\end{tabular}
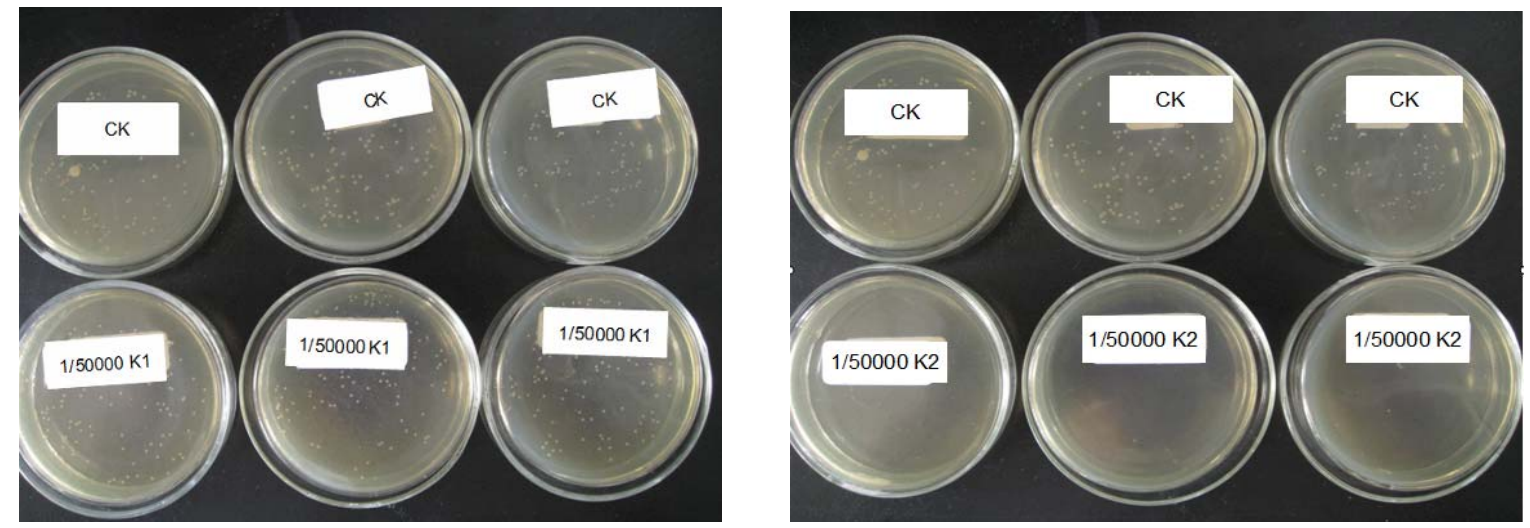

Figure 1. Effect of K1 \& K2 on the growth of tobacco Ralstonia Solanacearum at the concentration 1/50000. 


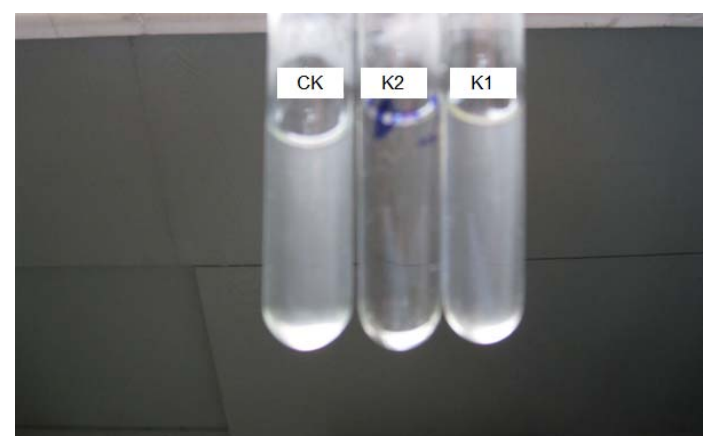

Figure 2. Comparison of $\mathrm{K} 1, \mathrm{~K} 2$ added in tobacco Ralstonia Solanacearum suspensions then cultured at $35^{\circ} \mathrm{C}$ for $10 \mathrm{~h}$.
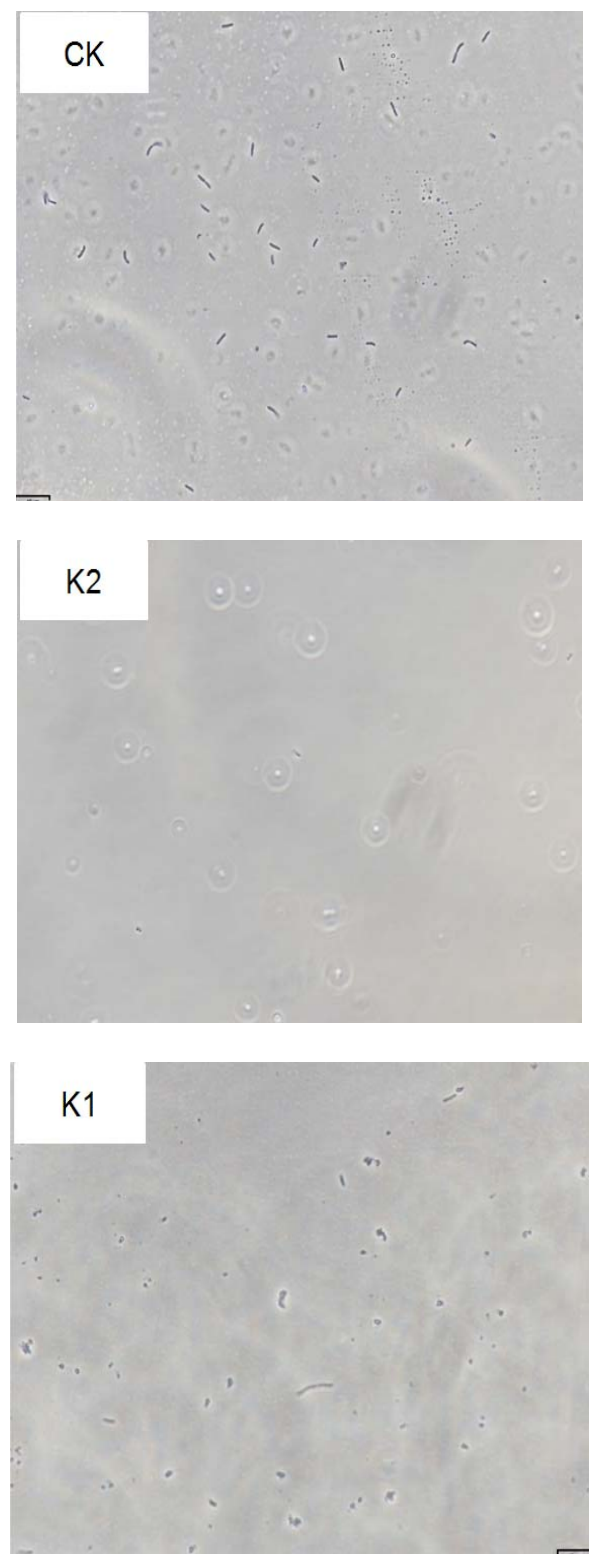

Figure 3. Effect of K1, K2 on Ralstonia Solanacearum individual morphology. under microscope can be observed in the presence of $\mathrm{K} 2$. While the shape of tobacco $R$. Solanacearum deformed and distorted in the presence of $\mathrm{K} 1$. All the results were congruent with the symptom of Figure 2.

\subsection{Effect of $\mathrm{K} 1$ and $\mathrm{K} 2$ on Seedlings Inoculated with Ralstonia Solanacearum}

The control effect of K1 and K2 on tobacco seedlings inoculated with $R$. Solanacearum was obvious from Figure 4. The left three cultures were sprayed with K1 $(1 / 1000$, one time) when they shown wilting 3 days later after inoculation, while the middle with water as control and the right with $\mathrm{K} 2(1 / 1000$, one time). There were two cultures shown severe wilting in control. The height and biomass of the third one were less than that of cultures of left and right although it shown no symptoms of wilting. The preliminary results indicated that $\mathrm{K} 1$ and $\mathrm{K} 2$ had a very significant effective suppression on bacterial wilting disease. Parameters such as disease incidence, index of variety and prevention effect were not included in this paper because the small size sample made no sense on that.

\section{Discussion and Conclusions}

K1 can inhibit the growth of tobacco $R$. Solanacearum completely at the concentration range from $1 / 50$ to $1 / 5000$. While at the concentration $1 / 50000, \mathrm{~K} 1$ had no significant differences compared with the control plates. Severe significant inhibitory effect (100\% inhibition rate) appeared in the presence of $\mathrm{K} 2$ at the concentration range from $1 / 50$ to $1 / 50000$. Further investigation is needed to determine the most effective minimum concentration of $\mathrm{K} 2$ on bacterial wilt pathogen. An appropriate concentration of K1 and K2 (1/20000) can deform and destroy the normal morphology of this tobacco bacterial wilting pathogen.

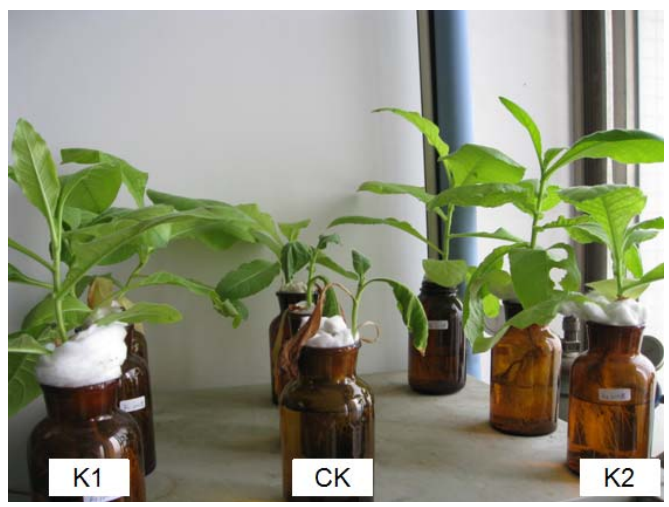

Figure 4. Effect of K1, K2 on the seedling tobacco inoculated with Ralstonia Solanacearum. 
To minimize the losses due to Granville wilt in field, the best management is precaution. It should be pointed out that $\mathrm{K} 1$ and $\mathrm{K} 2$ can't retrieve a situation when the infected tobacco-plantation field shows a large area of serve wilting or even dying. Once diagnosed as Granville wilt, the infected field needs treatment at once. Using K1 and $\mathrm{K} 2$ to control before vascular tissue blocked physically is very helpful and hopeful to suppress this pathogen and dredge vascular tissue so that the infected tobacco culture will recover to the normal state of growing.

Compared with the commercial streptomycin in agriculture, antibacterial agents like K1 and K2 have advantages of low dose and residue but high inhibition. Under the same condition of experiment, agricultural streptomycin $(1 / 4000)$ can only suppress one third of colonies formed on agar plates, while K1 (1/5000) and K2 $(1 / 50000)$ can inhibit the growth of tobacco R. Solanacearum completely. $\mathrm{K} 2$ is more effective than $\mathrm{K} 1$.

All the promising results are concluded from laboratory test under artificial management. What about the result if $\mathrm{K} 1$ and $\mathrm{K} 2$ are going to be used in tobacco field? How to exert these novel antibacterial agents to the highest extent according to different climates, geographic areas and subspecies of tobacco is needed to be done further. We have already collected nearly 50 tobacco samples (infected with $R$. Solanacearum) from 11 provinces (stretched from shandong province to guangzhou province) in China to test effects of these new K-series agents and some common agricultural streptomycin in the market (data not shown here). As new chemical anti-bacteria agents, people do not only pay attention on the inhibitory effects but also their effects on soil eco-system. Recently, effects of different concentrations of $\mathrm{K} 1$ and $\mathrm{K} 2$ on soil eco-system were investigated in a nearly 60-day experiment by studying soil microbial population, respiration rates and dehydrogenase activity (data not shown here). The results suggested that these new bactericidal agents had little influence on soil microbes and no side effects on soil environment at the lower concentration (for example $\mathrm{K} 1: 1 / 20000 \mathrm{ml} / \mathrm{g}$, $1 / 200000 \mathrm{ml} / \mathrm{g}$ ). In addition, the possible mechanism of antibacterial agents from K-series is also needed to be researched in future.

\section{Acknowledgements}

Authors thank all of those who contributed the strains or supported our field survey in this study.

\section{References}

[1] W. Tan and Y. H. Wu, "Pathology of Tobacco," China Agriculture Press, Beijing, 2003.

[2] S. F. Jenkins and C. W. Averre, "Root Diseases of Vegetables in Hydroponic Culture Systems in North Carolina Greenhouse," Plant Disease, Vol. 67, No. 9, 1983, pp. 968-970.

[3] T. P. Denny and A. C. Hayward, "Gram-Negative Bacteria Ralstonia," in: N. W. Schaad, J. B. Jones and W. Chun, Eds., Laboratory Guide for Identification of Plant Pathogenic Bacteria, 3rd Edition, APS Press, St. Paul, 2001, pp. 151-174.

[4] R. Chen, C. H. Gu and C. Y. Liu, "Preliminary Effect of Ten Kinds of Pesticides on Controlling Tobacco Bacterial Wilt," Yunnan Agriculture Science and Technology, Vol. 2008, No. 5, 2008, pp. 56-57.

[5] B. G. Oh and J. K. Yoo, “An Agent for Preventing Bacterial Wilt Comprises Streptomycin and Oxytetracycline and is Useful Especially for Preventing the Tomato Disease Caused by Ralstonia Solanacearum," KR2002081709-A, KR429159-B, 2002-10-30, 2004-04-29, South Korea.

[6] S. Zhang, H. T. Wu, X. J. Huo, et al., "Screening of Antagonistic Bacteria against Ralstonia Solanacearum and Determination of Their Antibacterial Activities," Tobacco Science \& Technology, Vol. 2007, No. 6, 2007, pp. 56-58.

[7] Y. Elad, "Biocontrol of Foliar Pathogens: Mechanisms and Application," Communications in Agricultural and Applied Biological Sciences, Vol. 68, No. 4a, 2003, pp. 17-24.

[8] T. Xiao and T. S. Yao, "Occurrence Characteristics of Tobacco Bacterial Wilt and Integrated Management," Yunnan Agriculture Science and Technology, Vol. 2008, No. 1, 2008, pp. 56-57.

[9] H. J. Peng, G. Gu, C. C. Ji, et al., "Relationship between State of a Disease in Field and Dynamic Monitoring of Ralstonia Solanacearum in Tobacco Root Soil," Journal of Hunan Agricultural University (Natural Sciences), Vol. 31, No. 4, 2005, pp. 384-387.

[10] G. Chen, G. Dong, Y. Dou, et al., "Integrated Control Method for Pseudomonas Solanacearum in Integrated Control Farm, Involves Determining Farming Measures by Draining Water with High Ridge and Deep Ditches, and Ditching Multiple Strips of Middle Channels per Acre," CN101601353-A, 2009-12-16, China.

[11] P. S. McManus , V. O. Stockwell, G. W. Sundin, et al., "Antibiotic Use in Plant Agriculture," Annual Review of Phytopathology, Vol. 40, 2002, pp. 443-465.

[12] D. Q. Zhou, "Microbiology: A Laboratory Manual," High Education Press, Beijing, 2006, p. 385. 